\title{
Correction to: Organising User Communities for Innovation Management
}

\section{Celine Schulz}

Author name is incorrectly captured in all chapters of this book. The correct author should be Celine Schulz. This has been corrected.

The updated online version of the original book can be found at https://doi.org/10.1007/978-3-8349-8711-2.

(C) Gabler | GWV Fachverlage GmbH, Wiesbaden 2019

C. Schulz, Organizing User Communities for Innovation Management, DOI 10.1007/978-3-8349-8711-2_6, 